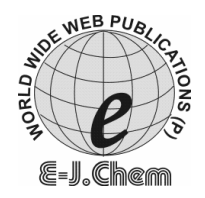

http://www.e-journals.net
ISSN: 0973-4945; CODEN ECJHAO

E-Journal of Chemistry

2009, 6(2), 399-411

\title{
Study on Designing Sulfur Containing Bifunctional Building Block with Improved Refractive Index
}

\author{
G. S. JHA, P. CHHABRA, G. SURI, M. TYAGI, \\ P. ARORA, G. SESHADRI and R. K. KHANDAL* \\ Shriram Institute for Industrial Research, \\ 19,University Road, Delhi-110007, India. \\ rkhandal@shriraminstitute.org
}

Received 31 July 2008; Revised 28 September 2008; Accepted 10 November 2008

\begin{abstract}
Sulfur and chlorine containing bifunctional diols with C-S bond has been prepared starting from chloroepoxy alkane and thioalcohol. The studies of FTIR, TLC, HPLC and NMR have been used to understand the reaction mechanism, as well as for optimization of the reaction parameters. The reaction is highly exothermic and the effect of temperature, rate of addition of reagents and reaction time are important factors affecting the formation of diol. Viscosity studies, HPLC, FTIR, NMR and acid number studies have shown that, these parameters could be used as process control parameters for the synthesis of diol. Refractive index of the synthesized diol is found to be higher than that of the reactants used.
\end{abstract}

Keywords: Diol, Thioether, Thioalcohol, Refractive index, Ring opening

\section{Introduction}

In recent times, high refractive index plastics have become materials of interest for various reasons, but mainly for the knowledge that such materials could be used for biomedical applications such as lightweight spectacle lenses of high diopters. In order to develop optical plastics of desired physicomechanical and chemical properties, it becomes essential that the process for manufacturing the basic raw materials for such materials is developed. It has been reported that for high refractive index, raw materials with bonds such as C-S, C-O and $\mathrm{C}-\mathrm{Cl}$ are desired. In the present study, the synthesis of raw materials with $\mathrm{C}-\mathrm{S}$ bond contributing to the refractive index has been optimized for the desired purpose.

Chlorine containing diol where a chlorine atom and C-S bond are present in the molecule has been synthesized from chloroepoxy alkane and thioalcohol. The effect of parameters such as reaction time and reaction temperature has been studied to obtain the incorporation of $\mathrm{C}-\mathrm{S}$ bond in the product with improved refractive index. 


\section{Experimental}

Thioalcohol with a purity of $99 \%$ was obtained from CDH Chemicals, Mumbai, India. Chloroepoxy alkane and trialkylamine having a purity of $99 \%$ were procured from s.d.fine Chem. Ltd., Mumbai, India. All the above chemicals were used as received.

HPLC analysis was carried out using Waters high performance liquid chromatographic system consisting of 515 modular pump, 486 UV- Visible detector \& equipped with Waters millenium software. Phenomenex C18 column with water:acetonitrile (95:5) at a flow rate of $1 \mathrm{~mL} / \mathrm{min}$ was used as the mobile phase. Thin layer chromatography (TLC) was carried out using aluminium sheets $(20 \mathrm{~cm} \times 20 \mathrm{~cm})$ coated with silica gel 60 . Methanol, water and acetic acid in the ratio of $(75: 15: 10)$ was used as mobile phase. Refractive index was determined using the Atago Abbe refractometer, model DR-M 4.

Viscosity studies were carried out using an Ostwald viscometer immersed in a constant temperature bath. IR analysis was carried out using Impact 410 spectrophotometer. Liquid cell was used for the IR analysis. Structural elucidation of diol was done by NMR spectroscopy ${ }^{13} \mathrm{C}$ NMR was done at CDRI, Lucknow, India. The amount of carbon (\%) and hydrogen, nitrogen, sulfur and oxygen contained in the synthesized diol was determined on the $\mathrm{C}, \mathrm{H}, \mathrm{N}, \mathrm{S}$ analyzer, model no. Vario EL-III.

The presence of sulfur was estimated ${ }^{1}$ gravimetrically by bomb calorimeter as per IS 1448:1991. The presence of chlorine/chloride was estimated ${ }^{2}$ as per ASTM-D808. The hydroxyl value was determined as per method described in the literature ${ }^{3}$. Acid number was determined $^{4}$ as per method IS 548: Part I.

\section{Preparation of diols}

One of the most successful routes to prepare diols is the ring opening reaction of the epoxy ring in the presence of different catalysts. Preparation of diols is achieved by the ring opening reaction of epoxides with water. Alcohols are used in the place of water, the ring opening leads to the formation of $\beta$ - alkoxy alcohols.

A very efficient and highly regioselective ring opening reaction of epoxides with benzoic acid and its derivatives in the presence of tetrabutylammonium bromide (TBAB) in anhydrous acetonitrile is reported to give selectively protected diols ${ }^{5}$ (Figure 1a).

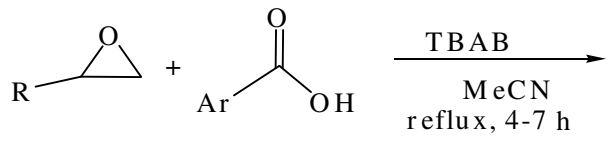<smiles>[Y]C(=O)OCC([R])O</smiles>

Figure 1(a). Ring opening reaction of an epoxide in the presence of tetrabutyl ammonium bromide in anhydrous acetonitrile.

Epoxides are known to undergo rapid ring opening with a range of alcohols in the presence of carbon tetrabromide under mild conditions to yield the corresponding $\beta$-alkoxy alcohols and 1,2-diols in high yields with high regioselectivity ${ }^{6}$ (Figure 1b).
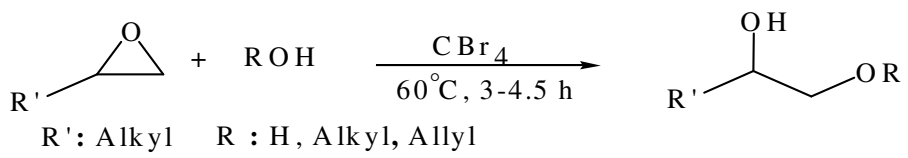

Figure 1(b). Ring opening reaction of an epoxide in the presence of carbon tetrabromide as catalyst. 
Epoxides are also cleaved under neutral conditions with water, alcohols and acetic acid in the presence of decatungstocerate(IV) ion, to form the corresponding diols in high yield ${ }^{7}$ (Figure 1c)

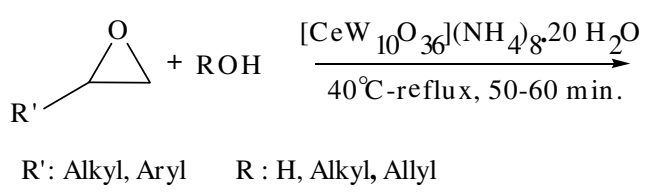<smiles>[R]OCC([R])O</smiles>

Figure 1(c). Ring opening reaction of an epoxide in the presence of catalyst; deca tungstocerate(IV) ion yielding diol in high yield.

From the above mentioned examples reported in the literature, it can be seen that diol can be synthesized from chloroepoxy alkane by controlling parameters such as time, temperature and catalyst. The reaction of chloroepoxy alkane involves a ring opening reaction, which in the presence of a base as a catalyst is instantaneous and highly exothermic. This knowledge can be used to synthesize diols with a C-S group, by using thiol instead of simple alcohol. This way, diols with groups like C-S and having an enhanced refractive index can be obtained which is the idea behind the present study. The possible reaction leading to the formation of diol with high refractive index can be envisaged as shown in Figure 2.

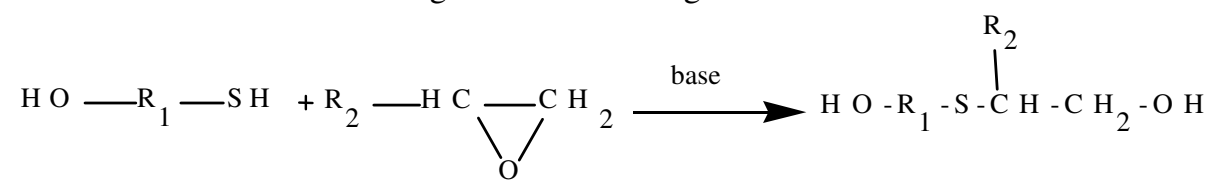

Figure 2. Ring opening of an epoxide ring in the presence of base forming a product with C-S bond.

A four necked, round bottom flask fitted with a stirrer, dropping funnel and thermometer pocket was used for the synthesis of diol. The synthesis was carried out in the presence of nitrogen. Chloroepoxy alkane was added to thioalcohol and trialkylamine under stirring.

\section{Results and Discussion}

Reaction parameters

The reaction between chloroepoxy alkane and thioalcohol was found to depend on factors such as the catalyst concentration, reaction temperature and reaction time.

\section{Effect of concentration of catalyst}

The result of effect of concentration of catalyst used for synthesis is presented in Table 1. Even though the ring opening is known to be catalyzed in both the acidic and basic medium, the initial studies conducted here showed better results when the reaction is carried out in the presence of a base. Thus, the synthesis of diol was carried out here in the presence of a base. Reaction was carried out in the absence and in the presence of a catalyst; with the concentrations varying from $0.5 \%$ to $1.0 \%$. In the absence of a catalyst, no reaction was found to take place since there was no increase in temperature, which is expected to occur due to exothermic reactions taking place when the epoxy ring gets opened. This confirms the fact that a catalyst is necessary to initiate the ring opening reaction of chloroepoxy alkane. The elemental analysis for different reaction mixtures show that for achieving a product with compositions close to the theoretical value of diol, $1 \%$ of the catalyst amount is required. The hydroxyl value of thioalcohol was found to be reduced from $21.7 \%$ to $18.5 \%$, which indicates the formation of diol. The hydroxyl value that was closest to the theoretical value is obtained with a catalyst amount of $1 \%$. 
Table 1. Effect of concentration of catalyst on diol synthesis in the presence of base.

(The product obtained after the reaction conducted for $1 \mathrm{~h}$ was analyzed for compositional analysis).

\begin{tabular}{ccccccc}
\hline S. No. & Catalyst, $\%$ & $\mathrm{C}, \%$ & $\mathrm{H}, \%$ & $\mathrm{~S}, \%$ & $\mathrm{Cl} \%$ & $\mathrm{OH}, \%$ \\
\hline 1. & 0.0 & -- & -- & 41.0 & 45.5 & 21.7 \\
2. & 0.2 & $31.2-32.0$ & 5.8 & $11.3-11.5$ & $15.2-15.5$ & 15.9 \\
3. & 0.5 & $31.5-32.0$ & 5.9 & $11.5-11.7$ & $15.3-15.5$ & 16.0 \\
4. & 0.7 & $32.0-33.0$ & 6.1 & $12.0-12.5$ & $15.5-15.8$ & 17.5 \\
5. & 0.8 & $32.0-32.5$ & 5.9 & $12.5-13.0$ & 15.5 & 18.0 \\
6. & 0.9 & $32.0-33.0$ & 6.0 & $12.5-13.0$ & 15.5 & 18.0 \\
7. & 1.0 & $33.0-34.5$ & $5.9-6.0$ & $17.0-17.5$ & $17.5-17.6$ & 18.5 \\
8. & Theoretical value of diol & 33.6 & 6.2 & 18.8 & 20.8 & 19.9 \\
9. & Thioalcohol & 30.7 & 7.6 & 41.0 & 0.0 & 21.7 \\
10. & Chloroepoxy alkane & 38.9 & 5.4 & 0.0 & 45.5 & 0.0 \\
\hline
\end{tabular}

\section{Effect of temperature}

The rate of addition of chloroepoxy alkane to thioalcohol affects the temperature of the reaction. The reaction can be maintained at the desired temperature by controlling the rate of addition of chloroepoxy alkane to thioalcohol. Drop wise addition helps in maintaining the temperature at the desired level, rapid addition of chloroepoxy alkane to thioalcohol results in a rapid increase of temerature up to $135^{\circ} \mathrm{C}$. Controlled addition helps in controlling the temperature of the reaction. Results of the effect of temperature on the formation of diol as well as the quality of diol are presented in Table 2 by adding chloroepoxy alkane to thioalcohol at different temperature conditions such as $25-30{ }^{\circ} \mathrm{C}, 30-35^{\circ} \mathrm{C}, 35-40{ }^{\circ} \mathrm{C}, 40-45^{\circ} \mathrm{C}$ and temperatures greater than $50{ }^{\circ} \mathrm{C}$.

Table 2. Effect of temperature on diol synthesis.

(The reaction was carried out for an hour at various temperature ranges and product obtained after the reaction was conducted for $1 \mathrm{~h}$ was analyzed for compositional analysis).

\begin{tabular}{|c|c|c|c|c|c|c|c|}
\hline S.No & Temp, ${ }^{\circ} \mathrm{C}$ & C, $\%$ & $\mathrm{H}, \%$ & $\mathrm{~S}, \%$ & $\mathrm{Cl}, \%$ & $\mathrm{OH}, \%$ & Remarks \\
\hline 1. & $25-30$ & $31.5-32.0$ & $6.0-6.1$ & $12.0-12.2$ & $15.3-15.5$ & 17.0 & $\begin{array}{c}\text { Colorless, clear and } \\
\text { viscous }\end{array}$ \\
\hline 2. & $30-35$ & $32.0-34.0$ & $6.1-6.3$ & $12.0-12.5$ & $15.4-15.5$ & 17.0 & $\begin{array}{l}\text { Colorless, clear and } \\
\text { viscous }\end{array}$ \\
\hline 3. & $35-40$ & $33.0-34.5$ & $5.9-6.0$ & $17.0-17.5$ & $17.5-17.6$ & 18.5 & $\begin{array}{c}\text { Colorless, clear and } \\
\text { viscous }\end{array}$ \\
\hline 4. & $40-45$ & $33.0-34.5$ & $5.9-6.0$ & $17.0-17.5$ & $17.5-17.6$ & 18.5 & $\begin{array}{c}\text { Pale yellow and } \\
\text { viscous }\end{array}$ \\
\hline 5. & $\begin{array}{l}\text { Uncontrolled } \\
\text { addition }\end{array}$ & $33.0-34.0$ & $5.9-6.0$ & $17.0-17.3$ & $17.4-17.5$ & 18.0 & $\begin{array}{l}\text { Dark yellow and } \\
\text { viscous liquid }\end{array}$ \\
\hline
\end{tabular}

From the results, it may be noted that the reaction is exothermic in nature as it undergoes an increase in temperature with the addition of chloroepoxy alkane to thioalcohol. If the temperature is not controlled, the end product is a dark yellow, viscous liquid. The addition of chloroepoxy alkane to thioalcohol without any control of temperature makes the temperature rise up to $135{ }^{\circ} \mathrm{C}$. This clearly indicates that the opening of the epoxy ring is an instantaneous and exothermic reaction. Here, it may be noted that the reaction does not occur in the absence of a catalyst. Due to the exothermic nature of the reaction between chloroepoxy alkane and thioalcohol, the reaction has been carried out under controlled temperature conditions. In order to understand the degree of conversion to diol, the following techniques were adopted: 
- $\quad$ NMR spectroscopy

- High performance liquid chromatography (HPLC)

- Thin layer chromatography (TLC)

- Infrared spectroscopy (IR)

From the analysis of chemical composition as shown in Table 1 and 2, it is quite evident that diol formation takes place; obviously by the opening of the epoxy ring and substitution at the least hindered carbon atom to obtain the diol. The two carbon atoms in the epoxide ring are highly susceptible to nucleophilic attack. The product obtained depends on the activity of the carbon which is preferentially attacked. In base catalyzed reactions, attack takes place at the less hindered carbon atom ${ }^{8}$. Since a base has been used for the reaction in the present study, substitution is expected to take place at the less hindered carbon to give the chlorine containing diol. This has been confirmed by NMR spectroscopy (Figure 3).

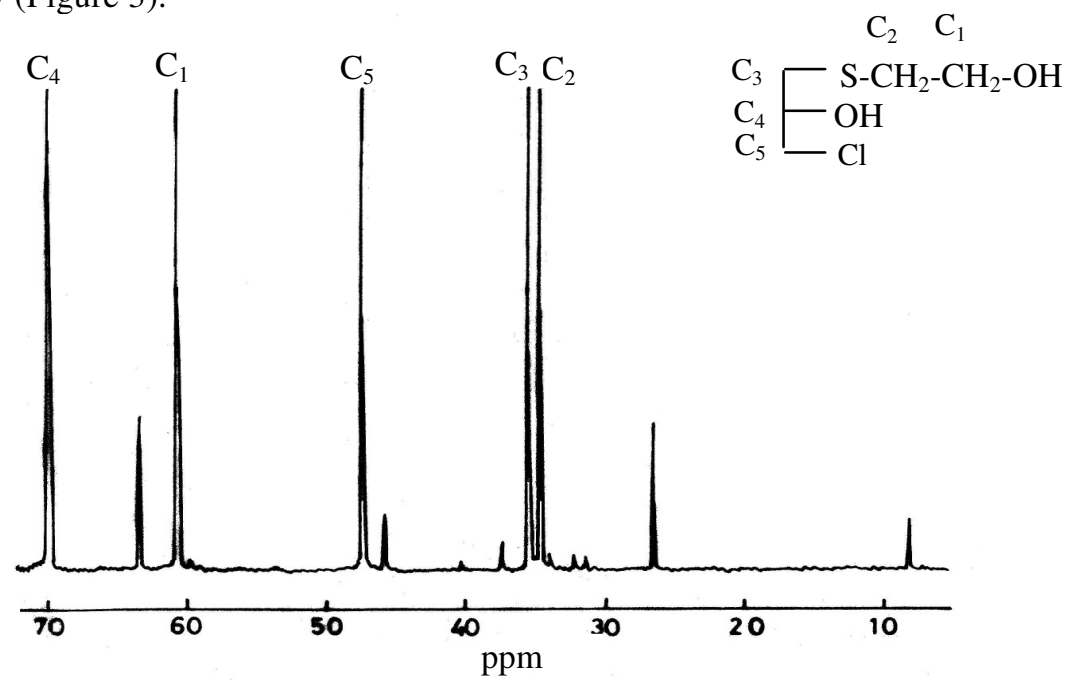

Figure 3. ${ }^{13} \mathrm{C}$ - NMR spectra of Diol.

(The sp3-hybridized carbon at $\mathrm{C}_{1}$ and $\mathrm{C}_{4}$ absorb up field and shows chemical shift value at $60.64 \mathrm{ppm}$ and $69.96 \mathrm{ppm}$ respectively. The carbon attached to chlorine $\mathrm{C}_{5}$ shows absorption at $47.34 \mathrm{ppm}$. Both $\mathrm{C}_{2}$ and $\mathrm{C}_{3}$, which are attached to sulfur atom, show a downfield absorption at $34.66 \mathrm{ppm}$ and $35.48 \mathrm{ppm}$ respectively.)

HPLC analysis of the end product obtained from the reaction conducted under uncontrolled temperature conditions show that within $15 \mathrm{~min}$ after the completion of the addition there is an absence of chloroepoxy alkane and thioalcohol in the product, thereby showing that the reaction between the two is immediate. On uncontrolled addition, the reaction product turns yellow, probably due to the formation of by products such as disulfides. The yellow color is not desirable and therefore, uncontrolled temperature is not favored. The HPLC results clearly indicate the disappearance of chloroepoxy alkane with the appearance of a peak due to the formation of diol (single component). The results of HPLC are presented in Figure 4.

Further, the diol synthesized at a temperature range of $35-40{ }^{\circ} \mathrm{C}$ was found to have similar values as compared to the theoretical values (Table 2). This indicates that a temperature range of $35-40{ }^{\circ} \mathrm{C}$ is required for diol formation. Moreover, addition of chloroepoxy alkane drop wise to the reaction mixture not only helped in maintaining the reaction temperature at $35-40{ }^{\circ} \mathrm{C}$ but it also resulted in the formation of a colorless product. 

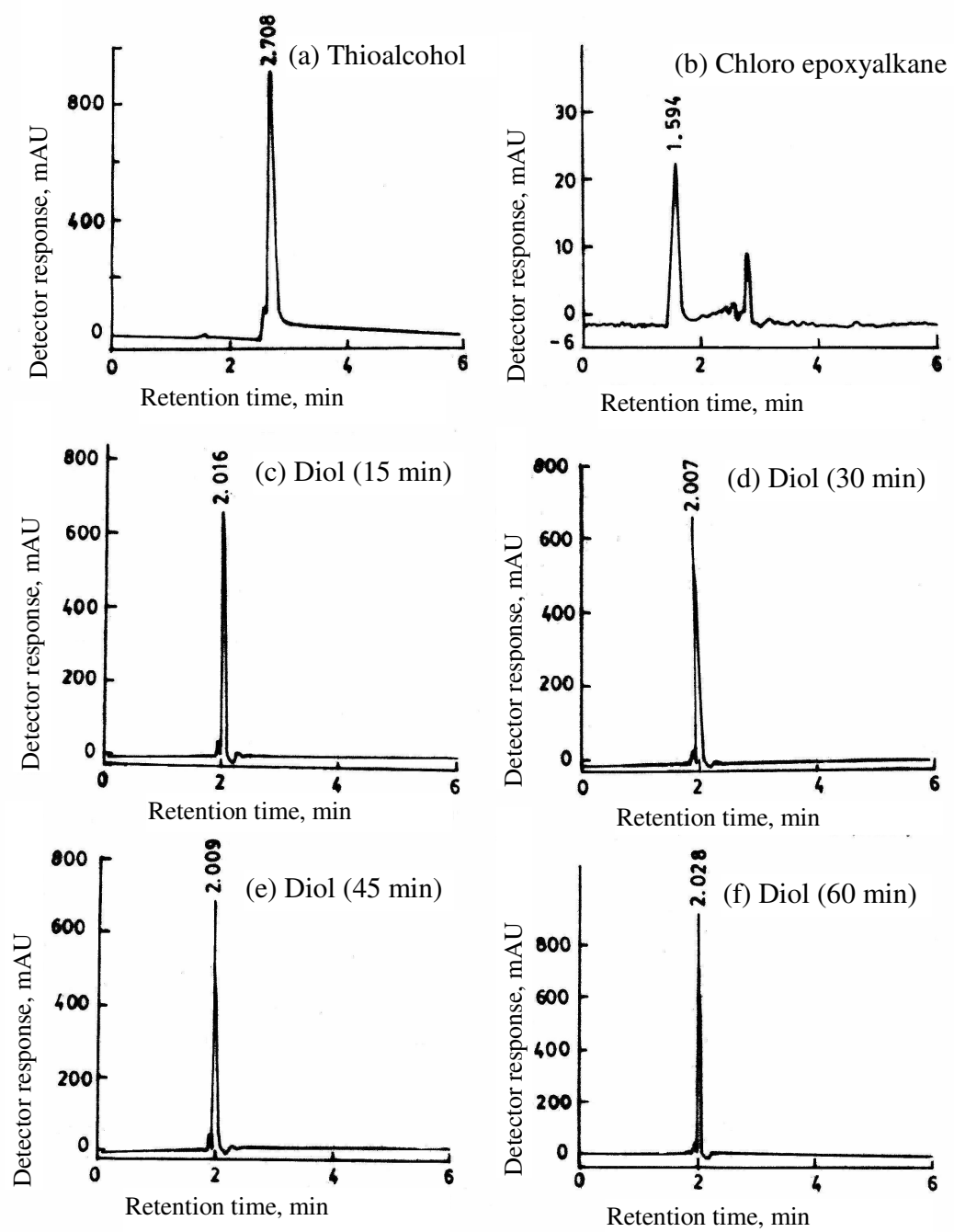

Figure 4. HPLC Spectra of diol synthesized without control of temperature, indicates that the ring opening takes place within 15 minutes.

The effect of temperature on diol synthesized at a temperature range of $25-30{ }^{\circ} \mathrm{C}$, 30-35 ${ }^{\circ} \mathrm{C}, 35-40{ }^{\circ} \mathrm{C}, 40-45{ }^{\circ} \mathrm{C}$ and without control of temperature is shown in Table 2 . In fact, before studying the effect of temperature, experiments were carried out to determine the temperature at which the ring opening takes place. Thus, the effect of temperature of addition starting from low temperature $\left(-40{ }^{\circ} \mathrm{C}\right)$ to higher temperature $\left(40{ }^{\circ} \mathrm{C}\right)$ as well as the effect of reaction temperature varying from -40 to $40{ }^{\circ} \mathrm{C}$ on diol formation was studied. The addition of chloroepoxy alkane was carried out at various temperatures: $-40{ }^{\circ} \mathrm{C},-15{ }^{\circ} \mathrm{C}, 0{ }^{\circ} \mathrm{C}, 20{ }^{\circ} \mathrm{C}$ and $40{ }^{\circ} \mathrm{C}$. After addition was completed, the reaction was allowed to take place for an hour at different temperatures. Reaction did not take place at $40{ }^{\circ} \mathrm{C},-15{ }^{\circ} \mathrm{C}, 0{ }^{\circ} \mathrm{C}$ and $20{ }^{\circ} \mathrm{C}$ as indicated by the hydroxyl value and viscosity of the product (Table 3). 
Table 3. Effect of low temperature on diol synthesis.

(Addition was done drop wise at a given temperature and then allowed to react at different temperatures for different periods of time from $15 \mathrm{~min}$ to $60 \mathrm{~min}$.)

\begin{tabular}{ccccccc}
\hline \multirow{2}{*}{ S.No. } & \multicolumn{2}{c}{ Temp, ${ }^{\circ} \mathrm{C}$} & \multicolumn{2}{c}{ Time, min. } & \multirow{2}{*}{ Viscosity (cSt) } & OH, \% \\
\cline { 2 - 5 } & Addition & Reaction & Addition & Reaction & & \\
\hline 1. & -40 & -40 & 15 & 15 & 23.48 & 21.7 \\
& -40 & -40 & 15 & 30 & 23.48 & 21.7 \\
& -40 & -40 & 15 & 60 & 23.48 & 21.7 \\
& -40 & $35-45$ & 15 & 60 & 119.25 & 19.9 \\
2. & -15 & -15 & 15 & 15 & 23.48 & 21.7 \\
& -15 & -15 & 15 & 30 & 23.48 & 21.7 \\
& -15 & -15 & 15 & 60 & 23.48 & 21.7 \\
3. & -15 & $35-40$ & 15 & 60 & 119.25 & 19.9 \\
& 0 & 0 & 15 & 60 & 23.48 & 21.7 \\
4. & 0 & $35-40$ & 15 & 60 & 119.25 & 19.9 \\
& 20 & 20 & 30 & 60 & 23.48 & 21.7 \\
5. & 20 & $35-40$ & 15 & 60 & 119.25 & 19.9 \\
& 40 & 40 & 15 & 15 & 43.57 & 21.7 \\
& 40 & $35-40$ & 15 & 60 & 119.25 & 19.9 \\
\hline
\end{tabular}

The hydroxyl value of the product is same as the hydroxyl value of the reactant i.e. thioalcohol (21.7\%) while the expected hydroxyl value of diol 19.99. Further, no change in the viscosity of the product is observed when the addition as well as the reaction is being conducted at low temperatures, confirming the ring opening reaction does not take place at temperatures lower than $20^{\circ} \mathrm{C}$. Moreover, the rise in temperature does not take place until the temperature of the reaction was kept above $30^{\circ} \mathrm{C}$. In other words, for the ring opening reaction of chloroepoxy alkane to take place, a temperature above $30{ }^{\circ} \mathrm{C}$ is essential. In fact, the reaction was observed to take place at temperatures above $35{ }^{\circ} \mathrm{C}$ as indicated by the hydroxyl value, viscosity studies and HPLC analysis. Viscosity studies were carried out during the synthesis of diol under the following reaction conditions:

a) Drop wise addition of chloroepoxy alkane to thioalcohol @ $5 \mathrm{~mL} / \mathrm{min}$ so that the temperature is maintained at less than $30^{\circ} \mathrm{C}$.

b) Addition of chloroepoxy alkane to thioalcohol @ $10 \mathrm{~mL} / \mathrm{min}$ which helps in maintaining the reaction temperature at $35-40{ }^{\circ} \mathrm{C}$.

c) Rapid addition of chloroepoxy alkane to thioalcohol ( $>10 \mathrm{~mL} / \mathrm{min})$ which results in a drastic increase of temperature up to $135^{\circ} \mathrm{C}$.

The graph for the viscosity studies under the above-mentioned conditions is given in Figure 5. The graph clearly shows that the viscosity of diol synthesized with uncontrolled temperature conditions is the maximum while the viscosity of diol synthesized with controlled temperature conditions increases uniformly till it reaches a maximum value. The study shows that the reaction when carried out at a temperature of $35-40{ }^{\circ} \mathrm{C}$ is the optimum range, as the viscosity remains fairly constant throughout the reaction.

The change in viscosity as shown in Figure 5 clearly indicates the formation of diol in the temperature range of $35-40{ }^{\circ} \mathrm{C}$. Increasing the temperature beyond $40{ }^{\circ} \mathrm{C}$, however, resulted in a yellow colored product probably due to the formation of disulfides as byproducts ${ }^{9}$. The results obtained from the above study clearly show that: 
1. For the reaction to take place by the opening of the epoxy ring, the temperature of the reaction must be kept above $30^{\circ} \mathrm{C}$.

2. If the temperature is allowed to exceed $35^{\circ} \mathrm{C}$, the product develops color. Temperatures above $40{ }^{\circ} \mathrm{C}$ lead to yellow color in the product.

3. The exothermic reaction must be controlled by maintaining the temperature within the range of $30-40{ }^{\circ} \mathrm{C}$ by removing heat from the system.

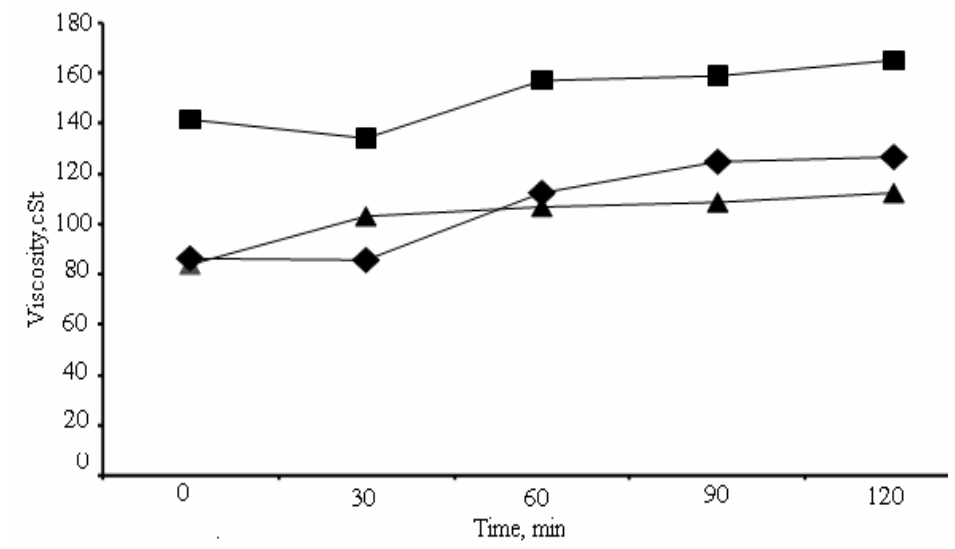

- (a) Addition@ $5 \mathrm{~mL} / \mathrm{min}$

$\Delta$ (b) Addition $@ 10 \mathrm{~mL} / \mathrm{min}$

(c) Addition@ @ $>15 \mathrm{~mL} / \mathrm{min}$

Figure 5. Effect of temperature conditions on viscosity of diol at dropwise addition of chloroepoxy alkane to thioalcohol.

The diol was analyzed for elemental content and hydroxyl value. The structure of the thioalcohol molecule indicates the probability of formation of isomers as shown in Figure 6. Once the ring in chloroepoxy alkane is opened up, substitution by the thioalcohol can take place at either of the carbon atom i.e. $\mathrm{C}_{1}$ or $\mathrm{C}_{2}$. When a base is used as a catalyst, the less hindered carbon atom is preferentially attacked ${ }^{8}$. This is indicated by TLC analysis, which has two spots with different $R_{f}$ factors; one having $R_{f}$ of 0.85 and another having an $R_{f}$ of 0.67. The results of the TLC analysis are presented in Figure 7.

\section{Effect of reaction time}

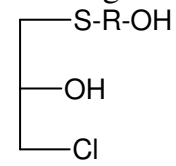

Figure 6. Possible isomers of diol.

After having determined the appropriate temperature range for the reaction as $35-40^{\circ} \mathrm{C}$, studies were carried out for finding out the time necessary for the conversion of the thioalcohol into diol. For this, therefore, the reaction was carried out at different time intervals by maintaining the temperature range between $35-40^{\circ} \mathrm{C}$. The effect of reaction time on diol has been studied by carrying out the reaction for various time intervals and analyzing the product for refractive index, specific gravity and acid number. FT-IR spectroscopy and HPLC analysis were also carried out.

The refractive indices of thioalcohol and chloroepoxy alkane are 1.50 and 1.43 respectively and after a reaction time of $60 \mathrm{~min}$, a refractive index of 1.53 was obtained (Table 4). 


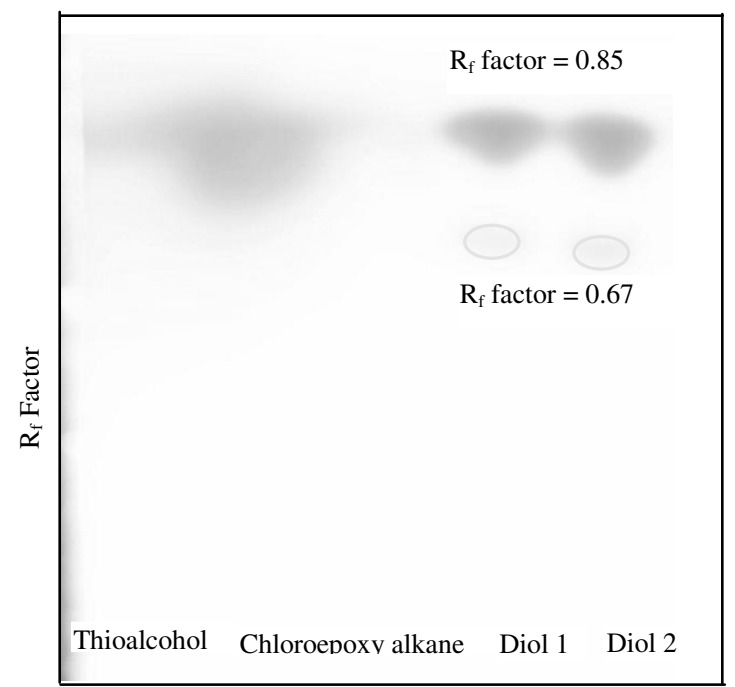

Figure 7. TLC spectra of diol (in duplicate). The TLC of the reactants (chloroepoxy alkane and thioalcohol) and product indicating the formation of diol as a major component in the reaction.

Table 4. Effect of reaction time on synthesis of diol. Temperature was maintained at 35$40{ }^{\circ} \mathrm{C}$ for the reaction and the product is analyzed at different time intervals after the addition of reactants is complete.

\begin{tabular}{|c|c|c|c|c|c|}
\hline S. No. & Time of reaction & $\mathrm{S}, \%$ & R. I. & Specific gravity & Acid number \\
\hline 1. & $30 \mathrm{~min}$. & -- & 1.526 & 1.274 & 5.8 \\
\hline 2. & $45 \mathrm{~min}$. & -- & 1.531 & 1.279 & 5.6 \\
\hline 3. & $1 \mathrm{~h}$ & 18.00 & 1.534 & 1.282 & 4.9 \\
\hline 4. & $1.5 \mathrm{~h}$ & 18.35 & 1.528 & 1.282 & 5.0 \\
\hline 5. & $2.0 \mathrm{~h}$ & 18.00 & 1.530 & 1.282 & 4.9 \\
\hline 6. & $\begin{array}{c}\text { Theoretical value } \\
\text { of diol }\end{array}$ & 18.80 & Not reported & Not reported & $<5.0$ \\
\hline 7. & Thioalcohol & 41.02 & 1.500 & 1.17 & 22.9 \\
\hline 8. & Chloro epoxyalkane & 0.0 & 1.430 & 1.18 & 0.0 \\
\hline
\end{tabular}

The refractive index increases only marginally indicating that the product formation takes place without any substantial change in the molar refraction. Refractive index is influenced by the intrinsic molar refraction of the bonds; no change in refractive index indicates that no new bonds are being formed during the reaction. This is obvious because formation of the diol is accompanied by incorporation of a $-\mathrm{OH}$ group in the diol which is not expected to bring any major change in the refractive index of diol. A rearrangement of the already existing bonds takes place to form the final product i.e. diol. Bonds such as $\mathrm{S}-\mathrm{H}$, $\mathrm{C}-\mathrm{S}$ and $\mathrm{O}-\mathrm{H}$, which are present in the reactants are present in the product also. The ring of the chloroepoxy alkane molecule opens up and the formation of a new bond is responsible for only a slight increase in refractive index. Increase in refractive index is observed only till $60 \mathrm{~min}$ of the reaction; beyond $60 \mathrm{~min}$, the refractive index is constant indicating the completion of the reaction (Figure 8). There is a marginal increase in refractive index indicating that the reaction has no significant effect on the intrinsic molar refraction of the various bonds. 


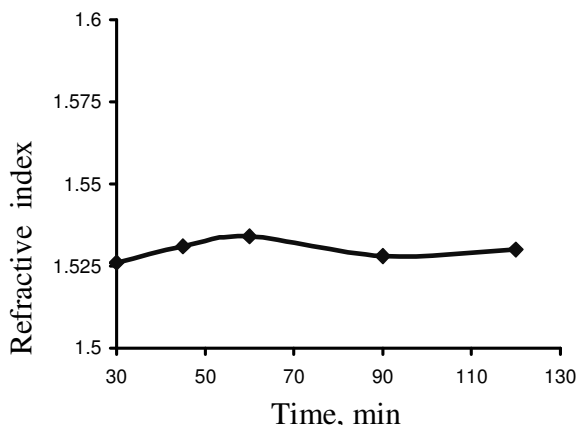

Figure 8. Effect of reaction time on refractive index of diol.

The formation of diol by the reaction of thioalcohol and chloroepoxy alkane has been studied by FTIR spectroscopy. The FT-IR analysis (Figure 9(a)) shows the presence of an $\mathrm{SH}$ group in thioalcohol as indicated by the presence of a peak at $2600-2550 \mathrm{~cm}^{-1}$. Epoxy group of chloroepoxy alkane appears (Figure 9(b)) in the $950-810 \mathrm{~cm}^{-1}$ region due to asymmetrical ring stretching during contraction of C-O bond of the epoxy ring. Analysis of the product at regular intervals of $15 \mathrm{~min}, 30 \mathrm{~min}, 45 \mathrm{~min}$ and $60 \mathrm{~min}$ was carried out. It can be seen that after $60 \mathrm{~min}$ of reaction time, none of the characteristic peaks due to the thioalcohol as well as chloroepoxy alkane are present in the product. The results are shown in Figure 9.

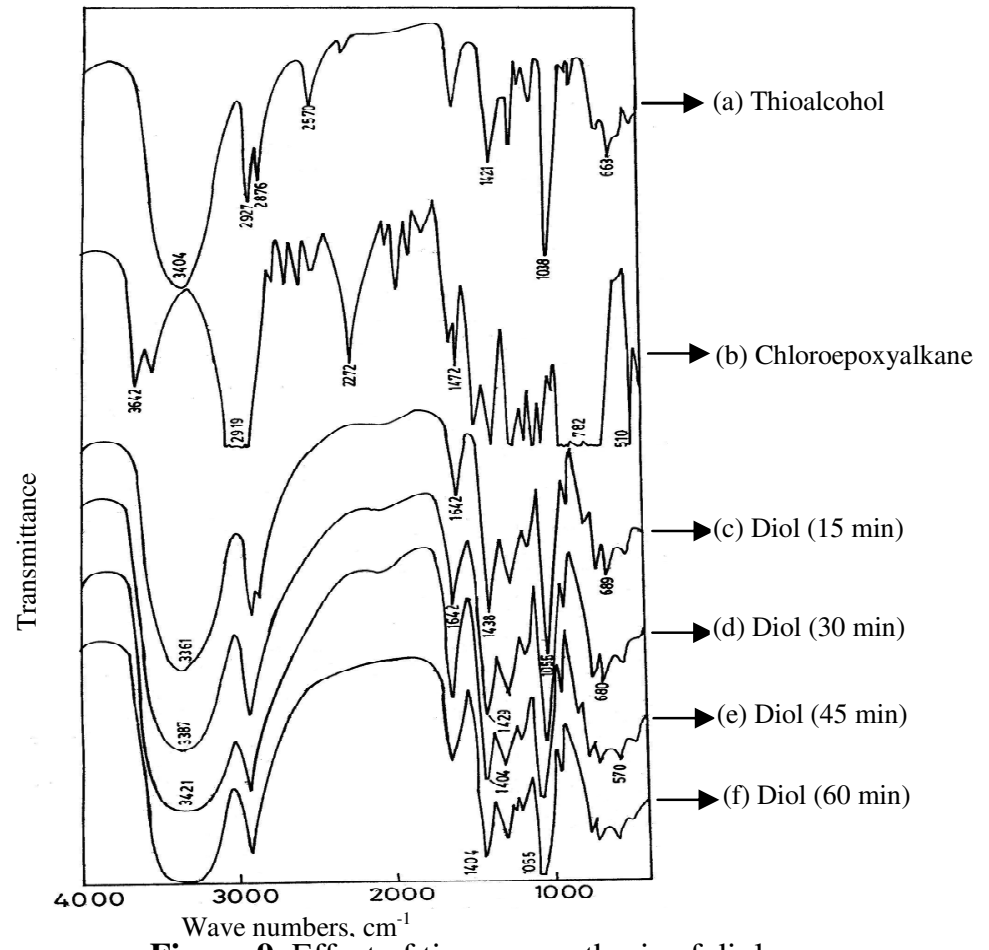

Figure 9. Effect of time on synthesis of diol.

(a) IR spectra of thioalcohol; characterized by the presence of a peak due to -SH group at $2570 \mathrm{~cm}^{-1}$. (b) IR spectra of chloroepoxy alkane characterized by the presence of C-O-C bond at $950-810 \mathrm{~cm}^{-1}$. (c)-(f) Effect of reaction time on diol formation. Absence of peak at $2570 \mathrm{~cm}^{-1}$ and $950-810 \mathrm{~cm}^{-1}$ indicating the reaction of epoxy group of chloroepoxy alkane to form diol within 15 minutes. 
Further, the completion of the reaction was confirmed by HPLC as shown in Figure 10. The results of the specific gravity show that there is an increase in specific gravity with an increase in reaction time. The highest value of specific gravity of 1.282 obtained for the reaction carried out for $60 \mathrm{~min}$ is much higher than the specific gravity of both the reactants; $1.115-1.116$ for thioalcohol and 1.180- 1.181 for chloroepoxy alkane. Beyond $1 \mathrm{~h}$, there is no change in the specific gravity. This confirms that the reaction is completed in $1 \mathrm{~h}$ (Figure 11).
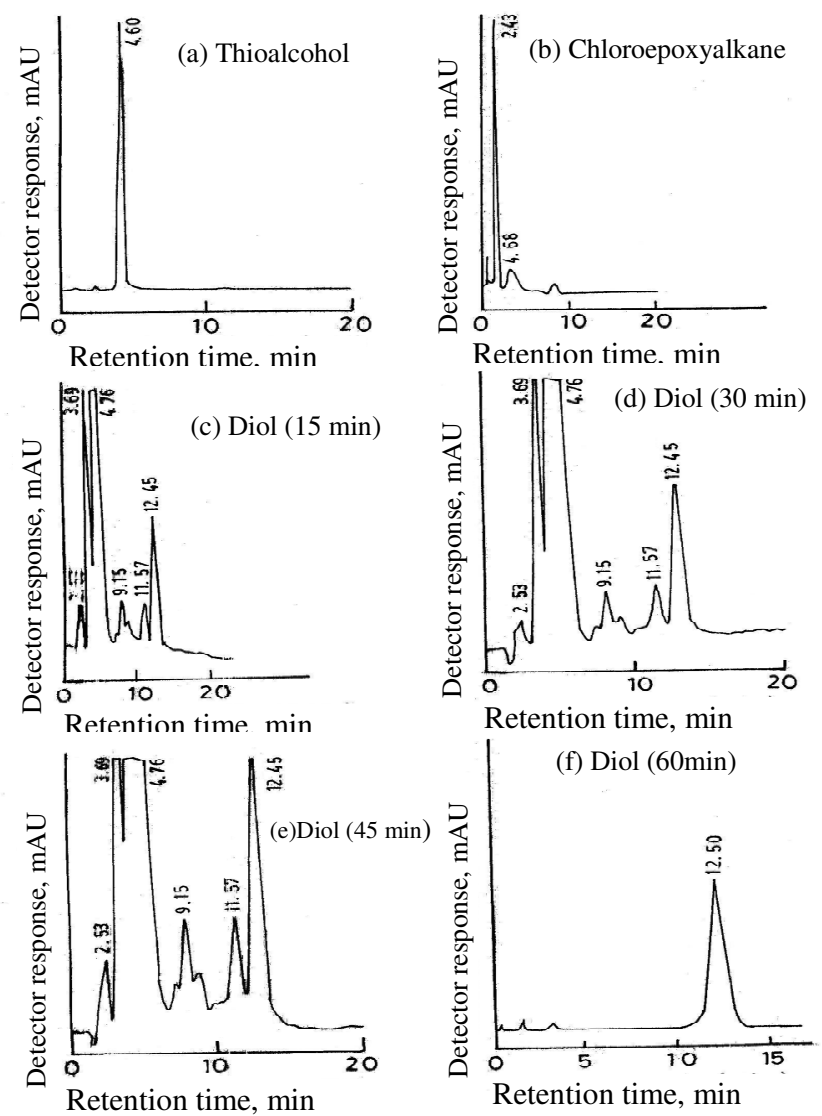

Figure 10. HPLC spectra of reactants and diol: indicates that the ring opening takes place within 15 minutes.

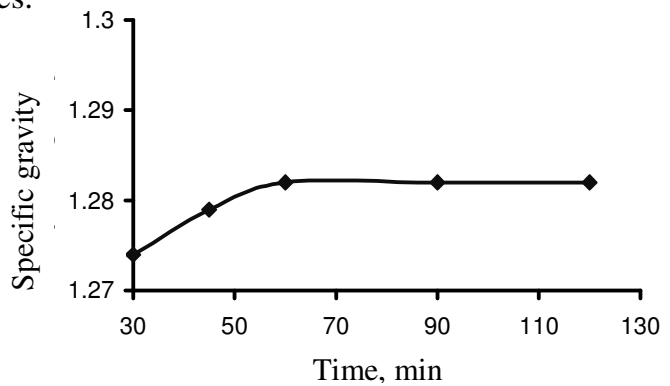

Figure 11. The effect of reaction time on the specific gravity of diol at different time intervals showing that the ring opening reaction of chloroepoxy alkane to form the diol. 
The results of acid number is another indication of the formation of diol. As evident from the values of acid number, the reaction appears to be completed even beyond $30 \mathrm{~min}$ with the acid number ranging from 4.4 to 5.0 at different time intervals. The acid number of the reactant (thiol) has been observed to come down from 22.9 to less than 5.0 indicating that the thiol has lost its acidic character during the reaction (Figure 12)

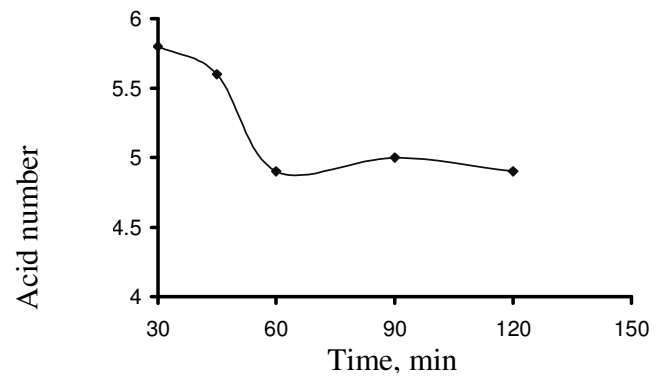

Figure 12. Effect of reaction time on acid number of diol. Acid number decreases to the value of 4.9 showing that whole of the reactant is being converted to the product: diol.

For better understanding it may be mentioned here that the thiol group exhibits acidic character due to the electronegativity of the sulfur atom in the $-\mathrm{SH}$ group. As a result, the thiol group releases the hydrogen ion easily, stabilizing the sulfide ion as given below in Equation (1):

$$
\mathrm{H}-\mathrm{S}-\mathrm{R}-\mathrm{OH} \longrightarrow \mathrm{H}^{+}+\ddot{\overline{\mathrm{S}}}-\mathrm{R}-\mathrm{OH}
$$

The release of $\mathrm{H}$ ion is the reason for an acid number value of 21.7 of the thiol studied here. When the thiol reacts with the chloroepoxy alkane followed by a reduction in acid number, it becomes evident that bond formation takes place with involvement of the $\mathrm{S}-\mathrm{R}-$ $\mathrm{OH}$ leading to non-availability of hydrogen ion. This can be understood from the structure of diol as shown in Figure 13.

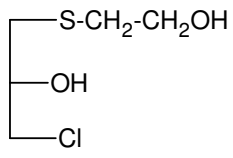

Figure 13. Structure of synthesized sulfur containing diol.

Structural elucidation of diols was also done by ${ }^{13} \mathrm{C}-\mathrm{NMR}$ spectroscopy. The NMR spectra confirmed diol to be the major product as shown in Figure 3. Peak positions agree closely with the theoretical values, thus confirming the structure of the diol. Peaks due to impurities were observed in the spectrum, which could be due to the fact that the diol has not been purified further by distillation. However, the diol synthesized in this manner did not interfere with the formation of the final product.

The NMR spectra as shown in Figure 3 indicate the presence of five major peaks which indicate the presence of five different carbon atoms (Table 5).

Table 5. Values of chemical shifts of carbons in different environment and their absorption.

\begin{tabular}{ccccc}
\hline & $\mathrm{C}_{2} \quad \mathrm{C}_{1}$ & Carbon & Chemical shift, ppm & Absorption \\
\cline { 2 - 5 } & $\mathrm{C} 1$ & 60.64 & Up field \\
$\mathrm{C}_{3}$ & $\mathrm{~S}^{-}-\mathrm{CH}_{2}-\mathrm{CH}_{2} \mathrm{OH}$ & $\mathrm{C} 2$ & 34.66 & Downfield \\
& & $\mathrm{C} 3$ & 35.48 & Downfield \\
$\mathrm{C}_{4}$ & $-\mathrm{OH}$ & $\mathrm{C} 4$ & 69.96 & Up field \\
$\mathrm{C}_{5}$ & $\mathrm{Cl}$ & $\mathrm{C} 5$ & 47.34 & Downfield \\
\hline
\end{tabular}


The $\mathrm{sp}^{3}$-hybridized carbon at $\mathrm{C} 1$ and $\mathrm{C} 4$ absorb upfield and show a chemical shift value of $60.64 \mathrm{ppm}$ and $69.96 \mathrm{ppm}$ respectively. There are five $\mathrm{sp}^{3}$ hybridized carbons in diol. The presence of substituents affects the nature of the absorption. There are three electronegative groups in diol with hydroxyl being the most electronegative followed by chlorine and sulfur. The carbon attached to chlorine $\mathrm{C} 5$ shows absorption at $47.34 \mathrm{ppm}$. Both $\mathrm{C} 2$ and $\mathrm{C} 3$, which are attached to sulfur atoms, show a downfield absorption at $34.66 \mathrm{ppm}$ and $35.48 \mathrm{ppm}$ respectively.

\section{Conclusion}

From this study, the following conclusions can be drawn:

1. Chloroepoxy alkane can be converted into a diol with the incorporation of a C-S bond, when reacted with thioalcohol.

2. The reaction of chloroepoxy alkane with thioalcohol is exothermic in nature and in the presence of a suitable catalyst the formation of diol is almost complete. For the desired quality of the product, the addition of reactants needs to be done in a controlled manner by controlling the rise in temperature.

3. The formation of diol can be confirmed by several process control parameters such as refractive index, acid number, viscosity and TLC besides instrumental analysis such as HPLC and NMR.

4. The refractive index of the product is significantly higher than the reactants indicating that such diols can serve the purpose of being used as the raw materials for development of materials with improved refractive index.

5. The findings of this study would provide a good reference base for development of materials with high refractive index.

\section{Acknowledgements}

The authors wish to express their sincere thanks to, Shri Tilak Dhar ji, Vice chairman, Shri J.P Kapur, Senior member, Governing Board, Shriram Institute for Industrial Research, India, for their guidance and support. The authors also acknowledge Department of Science and Technology, India, for their financial support.

\section{References}

1 Methods of Test for Petroleum and its Products: Sulfur By Bomb Method IS 1448, Part 33,1991

3 Standard Test Method for Chlorine in New and Used Petroleum Products (Bomb Method) - ASTM D 808,1991

4 Determination of Hydroxyl Content of Organic Compounds Adapted from the Acetic Anhydride Method of C.L. Ogg, W.L Porter and C.O Willits, Ind Emg Chem., Ed., $17,394,1945$

5 Methods of sampling and Test for oils and fats: Methods of sampling, physical and chemical tests IS-548, Part-I,1994

5 Khalafi-Nezhad A, Soltani Rad M N and Khoshnood A, Synthesis, 2003, 2552

6 Yadav J S, Reddy B V S, Harikishan K, Madan Ch and Narsaiah A V, Synthesis, 2005, 2897

7 Mirkhani V, Tangestaininejad S, Yadollahi B and Alipanah L, Tetrahedron, 2003, 59, 8213

8 Morrisson R T and Boyd R N, Organic Chemistry, 1983, 544.

9 Xan J, J Chem Soc., 1941, 63, 1130. 


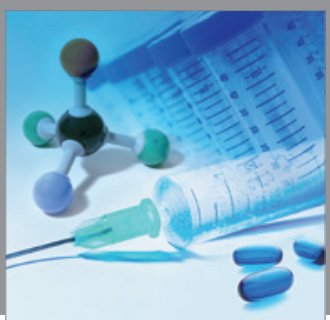

International Journal of

Medicinal Chemistry

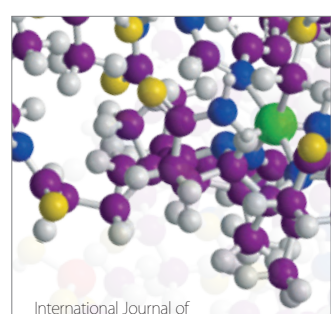

Carbohydrate Chemistry

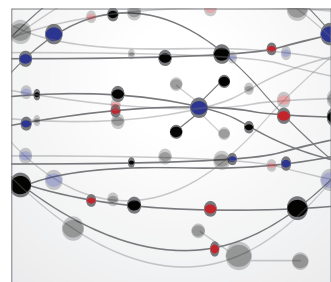

The Scientific World Journal
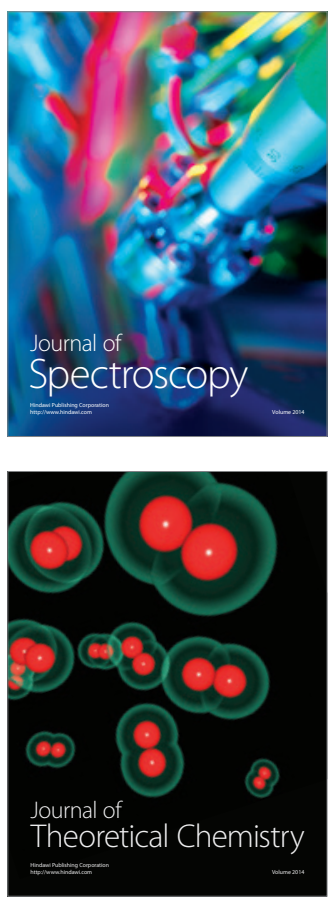
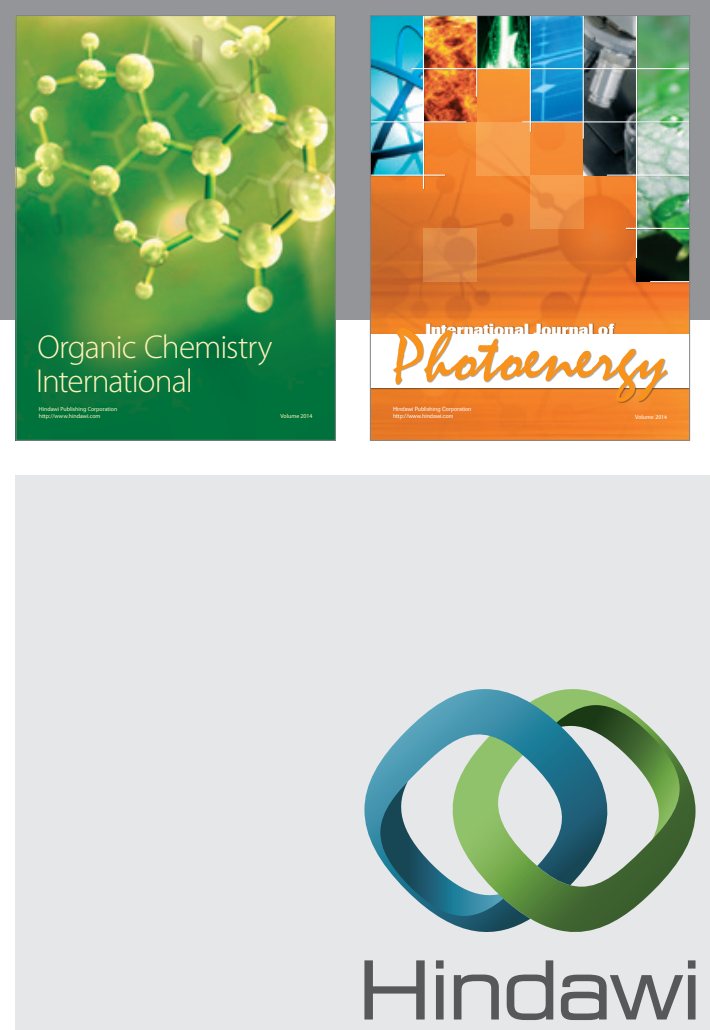

Submit your manuscripts at

http://www.hindawi.com
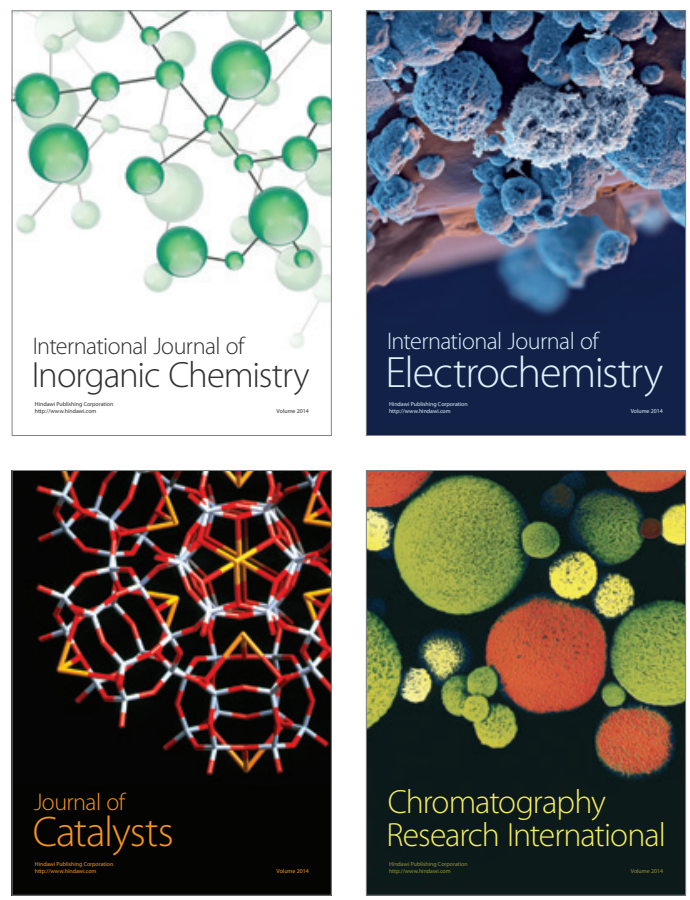
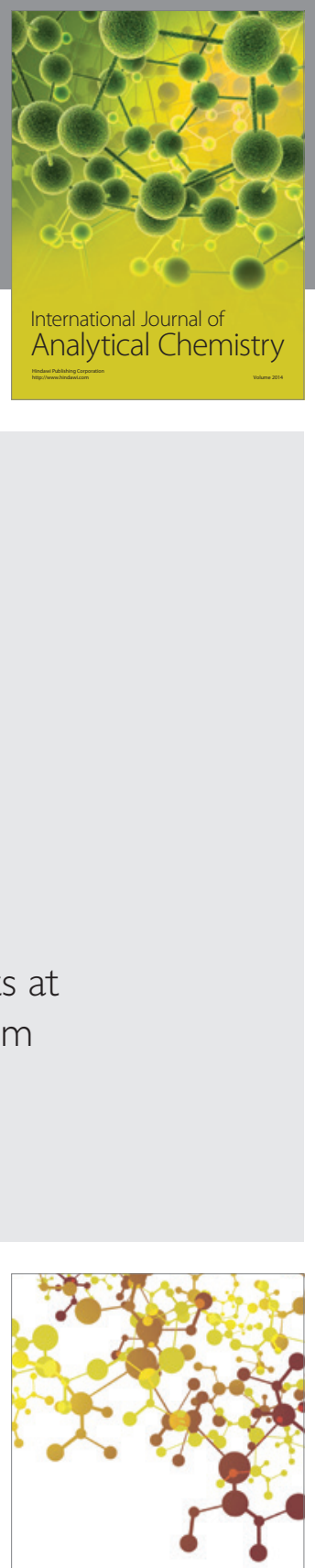

Journal of

Applied Chemistry
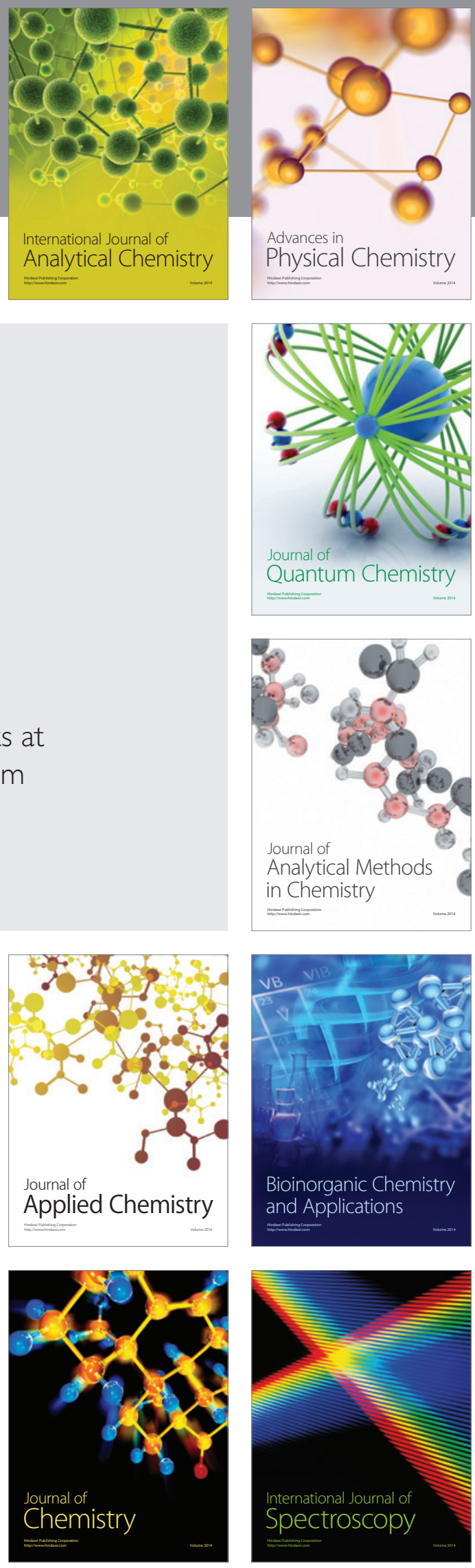